\title{
Study of dynamic changes in the parameters of liver function tests in COVID-19 patients: A hospital-based study in Eastern Nepal
}

Mittal $\mathrm{A}^{1 *}$, Farooqui MS ${ }^{2}$

*Corresponding author:

Dr. Ankush Mittal, Associate Professor, Department of Biochemistry, Birat Medical College Teaching Hospital, Nepal.

Email: drmittala@gmail.com $\underline{\text { ORCID }}$

Information about the article:

Received: Oct. 2, 2021

Accepted: Dec. 22, 2021

Published online: Dec. 31, 2021

Cite this article:

Mittal A, Farooqui MS. Study of dynamic changes in the parameters of liver function tests in COVID19 patients: A hospital-based study in Eastern Nepal. Journal of Biomedical Sciences. 2021; 8(2):60-64

\section{Publisher}

Nepal Health Research Society, Bashundhara -6 , Gokarnesowor Municipality, Kathmandu, Nepal eISSN 2382-5545, ISSN 2676-1343 (Print)

(C) The Author(s). 2021

Content licensing: CC BY 4.0

\section{ABSTRACT}

\section{Background}

COVID-19 has become a focus of healthcare practitioners worldwide after it was declared as a global pandemic. Although SARS-CoV-2 is primarily affecting the respiratory system, numerous studies have documented its impact on other organ systems, including the liver. This study aims to assess liver function in COVID-19 patients in light of SARS-CoV-2's extremely infectious and pathogenic character.

\section{Material and methods}

It was a hospital-based retrospective study conducted between January 1, 2021, and July 31, 2021, using data from the Department of Biochemistry at Birat Medical College Teaching Hospital in Nepal. Age, gender, total protein, albumin, AST, ALT, and the AST/ALT ratio were all measured.

\section{Results}

The median age of COVID-19 patients was 36 years (CI, $25-51), 60$ patients $(60.0 \%)$ were male, 31 patients $(31.0 \%)$ were obese, and 20 patients $(20 \%)$ had comorbidities, such as hypertension (14\%) and diabetes mellitus (6.0 \%). Compared to the non-critical group, the mean values of ALT, AST, ALP, GT, LDH, TBIL, and DBIL were significantly higher in the severe group. On the other hand, total protein and albumin were significantly lower in the severe group than the non-severe group.

\section{Conclusion}

In COVID-19, aberrant liver function, primarily AST increase, appears to be common. Therefore, direct viral hepatotoxicity during a systemic viral infection must be considered, as well as the possibility of sepsis or worsening of existing liver disease.

\section{Keywords}

Dynamic, COVID -19, Liver Function Test, Nepal, 


\section{Background}

Nearly every country in the world has now recorded COVID-19 cases. Early clinical studies, particularly from China, the United States, and Italy, have emphasised the main clinical symptoms of fever, cough, fatigue, and shortness of breath. However, a later study on the current pandemic coronavirus disease (COVID-19) uncovered hints about the disease's extrapulmonary manifestations [1]. These studies showed severe acute respiratory syndrome coronavirus 2 (SARS-CoV-2), a complicated clinical course or even viral infection could result in organ involvement and multi-organ failure. The liver is the principal organ for metabolism and detoxification, therefore maintaining normal performance is challenging with all available therapeutic methods for COVID-19 [2].

The liver has both the portal and systemic circulation, so it plays an essential role in the host's defence against microorganisms and is entangled in most systemic illnesses. Certain viruses have a direct cytotoxic effect on hepatocytes and cholangiocytes, albeit the pathophysiology appears to be multifactorial in most cases. For example, in earlier investigations, SARS-CoV has been shown to cause direct cytopathic liver injury rather than causing cellular stress via reduced oxygen supplies or cytokines, as seen in sepsis [3]. It will be critical to properly know the potential pathways involved in hepatic injury to optimise the treatment of COVID-19 and clinical decision making. In addition, liver biopsy specimens from one patient who did not survive from COVID-19 exhibited lobular activity, microvesicular steatosis, and portal activity [4].

Previous research has found that patients with SARS-CoV2 had a high frequency of aberrant liver function markers, particularly alanine aminotransferase and aspartate aminotransferase. Furthermore, some investigations have linked aberrant liver function indicators to clinical outcomes in COVID-19 patients, including more extended hospital stay, a higher risk of severe COVID-19, and mortality [5].

Abnormal liver function necessitates a clinical evaluation, ongoing monitoring, and, in some cases, particular therapy. As a result, determining the severity of liver injury in covid19 patients is critical. This study aims to assess liver function in COVID-19 patients in light of SARS-CoV-2's extremely infectious and pathogenic character.

\section{Material and methods}

\section{Study design and the participants}

It was a hospital-based study conducted between January 1st, 2021, and July 31st, 2021, using data from the Department of Biochemistry at Birat Medical College Teaching Hospital in Biratnagar, Nepal. Liver function test parameters of 100 COVID-19 patients who got admitted and underwent treatment in the hospital were retrieved from the hospital records and were used for the subsequent analysis.

\section{Data collection}

The following information was extracted from the medical records: gender, age, BMI, existing diseases like diabetes mellitus pulmonary disease. Standard liver blood chemistry was conducted at admission as well as during hospitalization.

\section{Inclusion criteria}

Patients with confirmed Real-Time Polymerase Chain Reaction for SARS-CoV-2 were included in this study.

\section{Exclusion Criteria}

Patients with pre-existing liver disease, alcoholics, Hepatitis $\mathrm{B}$, Hepatitis $\mathrm{C}$, those on drugs known to be hepatotoxic were excluded from the study.

\section{Estimation of total proteins}

The Biuret technique was used to determine total proteins [6].

\section{Estimation of albumin}

The albumin was determined using the BCG technique [7]. Estimation of total bilirubin and direct bilirubin: Jendrassik/Groff technique was used to calculate total and direct bilirubin [8].

\section{Estimation of AST and ALT}

A liquid UV test was used to estimate the transaminases (AST and ALT) [9].

\section{Sampling technique}

The sampling technique used in our study was the nonprobabilistic, convenience type. We used the total enumeration technique to retrieve the details of clinical and pathological information of the study subjects.

\section{Data management and statistical analysis}

The collected data was first entered in Microsoft Excel software (Microsoft Office 2013) where initial data management steps such as data cleaning were executed. Subsequently, data entry was done in the software SPSS (Statistical Package for Social Sciences) version 21 (SPSS Inc; Chicago, IL, USA). Regarding descriptive statistics, categorical and continuous data were described using frequency with percentage and mean with standard deviation, respectively. The Chi-square test was done to look at the relationship between the various variables. The significant difference between two variables was compared using the $\mathrm{t}$-test. To determine statistical significance, a 0.05 (two-tailed) p-value was employed.

\section{Ethical committee approval}

Ethical clearance was obtained from the Institutional Review Committee of Birat Medical College Teaching Hospital prior to the conduction of the study. 


\section{Results}

Table 1 shows that the median age of COVID-19 patients was 36 years $(\mathrm{CI}, 25-51)$, that 60 patients $(60 \%)$ were male, that 31 patients $(31 \%)$ were obese, and that 20 patients $(20 \%)$ had comorbidities, with hypertension (14\%) and diabetes mellitus being the most common (6\%). Six individuals with chronic liver illnesses were included in this investigation, including chronic hepatitis $B(n=3)$, alcoholic or nonalcoholic fatty liver disease $(n=2)$, and autoimmune liver disease $(n=1)$. Coronary artery disease $(n=3)$, chronic cardiac dysfunction $(n=1)$, and cardiomyopathy $(n=1)$ were all present in five of the individuals. Chronic obstructive pulmonary disease and chronic renal disease both follow the same path.

\begin{tabular}{lllll}
\hline \multicolumn{5}{l}{ Table 1: The study population's baseline } \\
characteristics
\end{tabular}

\begin{tabular}{|c|c|c|c|}
\hline \multicolumn{4}{|c|}{$\begin{array}{l}\text { Table 2: Evaluation of Liver function parameters o } \\
100 \text { patients based on their critical category }\end{array}$} \\
\hline Liver parameters & $\begin{array}{l}\text { Non critical } \\
\text { category (92) }\end{array}$ & $\begin{array}{l}\text { Critical } \\
\text { category (8) }\end{array}$ & p-value \\
\hline $\begin{array}{l}\text { total bilirubin ( } 5.1 \text { to } \\
17.0 \mathrm{mmol} / \mathrm{L} \text { ) }\end{array}$ & $\begin{array}{l}10.0(7.5 \\
12.5)\end{array}$ & $\begin{array}{l}12.6(10.5 \\
14.7)\end{array}$ & $0.001 *$ \\
\hline $\begin{array}{l}\text { direct bilirubin ( } 1.0 \text { to } \\
5.1 \mathrm{mmol} / \mathrm{L} \text { ) }\end{array}$ & $3.4(2.6,4.2)$ & $4.3(3.0,5.6)$ & $0.001 *$ \\
\hline $\begin{array}{l}\text { alanine transaminase } \\
\text { (U/L) 5-40 }\end{array}$ & $\begin{array}{l}22.0(14.0, \\
30.0)\end{array}$ & $\begin{array}{l}33.0(19.0, \\
47.0)\end{array}$ & $0.001 *$ \\
\hline $\begin{array}{l}\text { aspartate transaminase } \\
\text { (U/L) } 8-40\end{array}$ & $\begin{array}{l}26.0(17.0, \\
35.0)\end{array}$ & $\begin{array}{l}36.0(20.0, \\
52.0)\end{array}$ & $0.001 *$ \\
\hline AST/ALT ratio & $1.2(0.9,1.5)$ & $1.6(1.1,2.1)$ & $0.001 *$ \\
\hline Total protein $(6-8 \mathrm{~g} / \mathrm{dl})$ & $6.9(6.4,7.4)$ & $6.1(5.8,6.4)$ & $0.001 *$ \\
\hline Albumin $(3.5-5.0 \mathrm{~g} / \mathrm{dl})$ & $4.0(3.6,4.4)$ & $3.4(3.1,3.7)$ & $0.001 *$ \\
\hline Globulin $(2.5-3.5 \mathrm{~g} / \mathrm{dl})$ & $2.9(2.5,3.3)$ & $2.7(2.3,3.1)$ & $0.001 *$ \\
\hline Albumin/globulin ratio & $1.4(1.2,1.6)$ & $1.2(1.0,1.4)$ & $0.001 *$ \\
\hline $\begin{array}{l}\text { Alkaline phospahtase } \\
(25-140 \mathrm{U} / \mathrm{L})\end{array}$ & $\begin{array}{l}62.0(51.0 \\
73.0)\end{array}$ & $\begin{array}{l}66.5(57.8, \\
75.2)\end{array}$ & 0.223 \\
\hline$\gamma \mathrm{GT}$ (upto $30 \mathrm{U} / \mathrm{L}$ ) & $\begin{array}{l}24.0(15.0, \\
33.0)\end{array}$ & $\begin{array}{l}28.5(25.5 \\
31.5)\end{array}$ & 0.123 \\
\hline
\end{tabular}

$* p<0.05$, statistically significant

Table 2 shows that in the critical group, mean levels of alanine transaminase, aspartate transaminase, alkaline phosphatase, gamma glutamyl transpeptidase, lactate dehydrogenase, total bilirubin, and direct bilirubin were significantly higher than in the non-severe group. Total protein and albumin, on the other hand, were found to be significantly lower in the critical group when compared to the non-critical group. The $\mathrm{p}$ values reflect whether there are differences between the critical and non-critical groups. $\mathrm{p}<0.05$ was considered statistically significant.

\section{Discussion}

During the hospitalisation of severe critical COVID-19 patients, aberrant liver biochemical values and liver injury were discovered. Patients with aberrant hepatic biochemical markers and liver damage had higher AST, ALT, total bilirubin, gamma GT, and ALP values than patients with normal liver biochemical parameters. COVID-19 patients' liver impairment can be ascribed to a variety of secondary illness consequences, as well as the underlying infection. Alternative etiologies for COVID-19 include systemic inflammatory reaction and cytokine storm., these secondary consequences include drug-induced liver injury, hepatic ischemia, hypoxia, and shock.

ALT and AST abnormalities were found in $22.0 \mathrm{IU} / \mathrm{L}$ (14.0, $32.0)$ and $26.0 \mathrm{IU} / \mathrm{L}(20.0,32.0)$ in the non-critical group of 100 patients with COVID-19. ALT and AST readings, 33.0 IU/L (19.0, 47.0) and 36.0 IU/L (20.0, 52.0), respectively, increased significantly in the critical group during their hospital stay. In comparison, our results are in line with those of Kulkarni et al. [10].

Although less prevalent elevations in ALP 62.0 U/L (51.0, $73.0)$ in the non-critical group and $66.5 \mathrm{U} / \mathrm{L}(57.8,75.2)$ in the critical group, this study found that the pattern of abnormal liver function tests is largely hepatocellular rather than cholestatic. The difference was not significant in $\gamma \mathrm{GT}$ between the non-critical group $(24.0 \mathrm{U} / \mathrm{L}(15.0,33.0)$ and the critical group $(28.5 \mathrm{U} / \mathrm{L}(25.5,31.5)$. Given that the entrance receptor for SARS-CoV-2, angiotensin-converting enzyme-2 (ACE2), is considerably more abundantly expressed in cholangiocytes than in hepatocytes [11], our findings imply that the SARS- CoV-2's cytopathic effect may not be the predominant mechanism of related liver damage. Apart from the virus's direct cytopathic effect, hepatic dysfunction in COVID-19 might be linked to an uncontrolled immunological response, drug-induced liver injury, or sepsis [12].

In severely ill SARS-CoV-2 patients, abnormal hepatic biochemical markers are linked to an increased risk of death. As a result, these signs should be constantly evaluated during the hospital stay, with special emphasis dedicated to liver damage.

\section{Conclusion}


In COVID-19, aberrant liver function, primarily AST increase, appears to be common. Direct viral hepatotoxicity during a systemic viral infection must be considered, as well as the possibility of sepsis or worsening of an existing liver disease.

\section{Limitation and future scope of the study}

Due to the study design, our research fails to elicit the causal relationship between the different pathological features as seen in COVID-19 patients. Additionally, in such a design, the sample size of 100 decreases the power of the associations as depicted. Despite these apparent limitations, the present study's findings pave a pathway for further scrutiny of the relationships between the different variables of interest, with a more improvised study design, such as a longitudinal study.

\section{Relevance of the study}

In the face of COVID-19 pandemic where emergence of new variants of the SARS-CoV-2 poses a constant challenge to the medical community at large, the findings of this study could serve as a foundation for clinicians in planning the proper management of the patients.

\section{Abbreviations}

Alkaline Phosphatase (ALP), Aspartate Transaminase; ALT: Alanine Transaminase (AST), Body Mass Index (BMI), Chronic Heart Disease (CHD), Chronic Kidney Disease (CKD), Chronic Liver Disease (CLD), Chronic Pulmonary Disease (CPD), Corona Virus Disease - 19 (COVID-19), direct bilirubin (DBIL), Gamma Glutamyl Transpeptidase $(\gamma-\mathrm{GT})$, Severe Acute Respiratory Syndrome Corona Virus - 2 (SARS-CoV-2), total bilirubin (TBIL)

\section{Acknowledgments}

Our sincere thanks go to the department of Biochemistry, Central Clinical Laboratory of Birat Medical College Teaching Hospital for the support in retrieval of the data for the study.

\section{Authors' contribution}

a. Study planning: AM, MSF

b. Data collection: AM, MSF

c. Data analysis/ interpretation: AM, MSF

d. Manuscript writing: AM, MSF

e. Manuscript revision: AM, MSF

f. Final approval: AM, MSF

g. Agreement to be accountable for all aspects of the work: AM, MSF

\section{Funding}

No funding has been obtained to conduct the study.

\section{Availability of data and materials}

All data and material of this study are a part of this article.

\section{Competing interests}

None declared.

\section{Publisher's Note}

NHRS remains neutral with regard to jurisdictional claims in published maps and institutional affiliations.

The publisher shall not be legally responsible for any types of loss, actions, claims, proceedings, demand or costs or damages whatsoever or howsoever caused arising directly or indirectly in connection with or arising out of the use of this material.

\section{Author information}

${ }^{1}$ Dr. Ankush Mittal, Associate Professor, Department of Biochemistry, Birat Medical College Teaching Hospital, Nepal, ORCID

${ }^{2}$ Mohammad Shamim Farooqui, Department of Emergency Medicine, Paras HMRI Hospital, Patna ORCID

\section{References}

1. Behzad S, Aghaghazvini L, Radmard AR, Gholamrezanezhad A. Extrapulmonary manifestations of COVID-19: Radiologic and clinical overview. Clin Imaging 2020 ;66:35-41. https://doi.org/10.1016/j.clinimag.2020.05.013

2. Zou M, Su X, Wang L, Yi X, Qiu Y, Yin X et al. The Molecular Mechanism of Multiple Organ Dysfunction and Targeted Intervention of COVID19 Based on Time-Order Transcriptomic Analysis. Front Immunol. $2021 ; 12: 729-776$. https://doi.org/10.3389/fimmu.2021.729776

3. Jothimani D, Venugopal R, Abedin MF, Kaliamoorthy I, Rela M. COVID-19 and the liver. J Hepatol. 2020 ;73:1231-1240. https://doi.org/10.1016/j.jhep.2020.06.006

4. Lizardo-Thiebaud MJ, Cervantes-Alvarez E, Limon-de la Rosa N, Tejeda-Dominguez F, Palacios-Jimenez M, Méndez-Guerrero $\mathrm{O}$ et al. Direct or Collateral Liver Damage in SARS-CoV2-Infected Patients. Semin Liver Dis. 2020 ;40:321-330. https://doi.org/10.1055/s-0040-1715108

5. Xu W, Huang C, Fei L, Li Q, Chen L. Dynamic Changes in Liver Function Tests and Their Correlation with Illness Severity and Mortality in Patients with COVID-19: A Retrospective Cohort Study. Clin Interv Aging 2021;16:675-685. https://doi.org/10.2147/CIA.S303629

6. Weichselbaum TE. An accurate and rapid method for the determination of proteins in small amounts of blood serum and plasma. Am J Clin Pathol 1946;10:40-9. 
https://doi.org/10.1093/ajcp/16.3 ts.40

7. Doumas BT, Watson WA, Biggs HG. Albumin standards and the measurement of serum albumin with bromcresol green. Clin Chim Acta 1971;31(1):87-96.

https://doi.org/10.1016/0009-8981(71)90365-2

8. Garber CC. Jendrassik--Grof analysis for total and direct bilirubin in serum with a centrifugal analyzer. Clin Chem $1981 ; 27(8): 1410-6$. https://doi.org/10.1093/clinchem/27.8.1410

9. Henley KS, Pollard HM. A new method for the determination of glutamic oxalacetic and glutamic pyruvic transaminase in plasma. J Lab Clin Med 1955;46:785-9.

10. Kulkarni AV, Kumar P, Tevethia HV, Premkumar M, Arab JP, Candia R, et al. Systematic review with meta-analysis: liver manifestations and outcomes in COVID-19. Vol. 52, Alimentary Pharmacology \& Therapeutics. Wiley; 2020. p. 584-99.

https://doi.org/10.1111/apt.15916

11. Beyerstedt S, Casaro EB, Rangel ÉB. COVID-19: angiotensin-converting enzyme 2 (ACE2) expression and tissue susceptibility to SARS-CoV2 infection. Eur J Clin Microbiol Infect Dis. 2021;40:905-919.

https://doi.org/10.1007/s10096-020-04138-6

12. Jothimani D, Venugopal R, Abedin MF, Kaliamoorthy I, Rela M. COVID-19 and the liver. J Hepatol. 2020;73:1231-1240.

https://doi.org/10.1016/j.jhep.2020.06.006 